\title{
Design and Analysis of HPFRCC Blast Resistant Structures
}

\author{
Geethu Elsa Thomas ${ }^{1}$, Sithara. $\mathbf{S}^{2}$ \\ ${ }^{1}$ PG Scholar, Structural Engineering, SBCE \\ ${ }^{2}$ Assistant Professor, Department of Civil Engineering, SBCE
}

\begin{abstract}
In the past few years, the increase in the number of terrorist attacks has shown that the effect of blast loads on buildings is a serious matter that should be taken into design consideration. These man-made disasters has created a challenge to structural engineers world over about the deficiency in the design process. Blast loads are extreme, instaneous, unpredictive impulses acting over milliseconds. Due to this nature of blast loads, it is complicated to analyse the dynamic responses of the structures. Usage of advanced engineering materials for construction can solve these structural problems to an extent. This paper presents the design and analysis of an underground blast resistant shelter made up of high performance fiber reinforced cementitious composites (HPFRCC). This research focuses on an alternative section of cylindrical module of the shelter. The dynamic behavior of module under blast load is studied in finite element software Abaqus CAE 6.12. It is observed that the material stress-strain behavior is greatly influenced by strain rates of loadings. Shelter manually designed using codes in limit state method is verified with the analytical analysis.
\end{abstract}

Keywords: blast loads, dynamic responses, high performance fiber reinforced cementitious composites, strain rate etc

\section{Introduction}

An explosion is a very fast chemical reaction producing transient air pressure waves called blast wave. When the explosive is caused to react, it decomposes violently with enormous amount of heat and gas being generated. The rapid expansion of this gas results in the generation of shock waves. Generally four categories of blasts are possible, namely, air blast, surface blast, underground blast, and underwater blast. Surface blast occurs very near or on the ground surface. The initial shock wave is reflected and amplified by the ground surface to produce a reflected wave. Here, the reflected wave merges with the incident wave which is hemispherical in shape at the point of detonation and forms a single wave, as shown in Figure1.

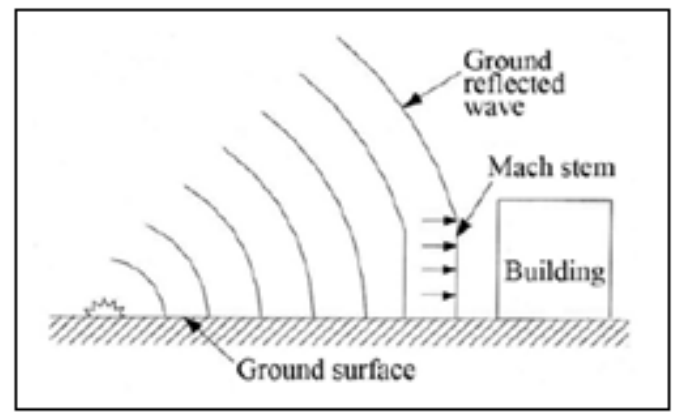

Figure 1: Surface blast

As the shock wave continues to propagate outwards along the ground surface, a front commonly called a Mach stem is formed by the interaction of the initial wave and the reflected wave. The effective yield of a surface burst is almost double of an equal explosion high in the air. This condition is taken in the present study since it is assumed to give most serious effects.

The behavior of materials used under blast application depends on their mechanical properties under such high strain rates of loadings. It is observed that material stress- strain behavior is greatly influenced by strain rates. Under high strain rates, the materials exhibit stiffer constitutive behavior, resulting in improved mechanical properties. Steel fiberous reinforced cement concrete (SFRCC), which comes under the category of HPFRCC is taken in the present study as the construction material. SFRCC has ability to withstand repeatedly applied shock or impact loading and has a superior resistance to cracking and crack propagation. These fiber composites possess increased extensibility and tensile strength and are able to hold the matrix together even after extensive cracking.

In order to understand the blast-resistant capacity and find out the main factors that influence the blast-resistant behavior, the nonlinear dynamic responses of the cylindrical module should be analysed. Analyses on the effect of blast loading on underground structures have been carried out by many researchers, Abaqus/CAE 6.12 is identified as an appropriate software for finite element analysis of the system. The below-ground structures are classified into buried and semi-buried structures depending upon the earth cover and slopes of earth berms. The buried structure, which is taken in the present study is subjected only to the general overpressure, the reflected and dynamic pressures is neglected. The principal structural consideration in design of buried pipe is the ability to support all imposed loads. Experimental investigation on the responses of underground cylinder subjected to blast loading often becomes difficult due to socio-political issues. Thus, advanced numerical analysis of the system subjected to blast loading is of utmost importance.

\section{Literature Survey}

[1] Manmohan Dass Goe and Vasant A. Matsagar (2014) Various strategies for blast mitigation are reviewed. Emphasis has been laid on the mechanics of the sacrificial blast wall and design using various materials used for its 


\section{International Journal of Science and Research (IJSR) \\ ISSN (Online): 2319-7064}

Index Copernicus Value (2013): 6.14 | Impact Factor (2015): 6.391

construction. The various lightweight materials used for this purpose further add to increase blast resistance in comparison with conventional materials.

\section{[2] Slawson T. R. \& Davis, J.L}

Developed an underground reinforced concrete blast shelter for 100 men to resist the air blast (peak overpressure of 50 psi) and radiation effects of $1 \mathrm{Mt}$ nuclear surface detonation. The design was validated by conducting small scale static and dynamic tests.

[3] Homes .R. L.oodson, S.C. \& Slawson, T. R. Tested an 18-man blast shelter for 200 psi peak overpressure level generated by $8 \mathrm{Kt}$ high explosive detonation. The shelter was made of 10 gauge galvanized corrugated steel sheets. Study of shock spectra indicated that occupant's survivability was highly probable with little or no injuries and that the survivability of generators and communication equipment could be achieved by shock isolation.

[4] Rohit Tiwari, Tanusree Chakraborty \& Vasant Matsagar (2014) conducted three dimensional nonlinear finite element (FE) analyses of underground tunnels in soil subjected to internal blast loading. The coupled EulerianLagrangian (CEL) analysis tool in finite element software Abaqus/Explicit has been used for the analysis purpose.

It is observed from the results that pressure acting on the tunnel lining increases with the increase in charge weight. Both the lining and the surrounding soil undergo significant deformation. Deformation of the tunnel lining decreases with increasing lining thickness. Also, deformation of tunnel lining and soil decrease with increasing friction angle of soil.

[5] P. Kmiecik, M. Kaminski (2011) Parameters needed to correctly model concrete under compound stress are described in this paper. The parameters are illustrated using the Concrete Damaged Plasticity (CDP) model included in the ABAQUS software. The CDP model makes it possible to define concrete for all kinds of structures.

\section{Objective of the Work}

For a specific underground blast resistant shelter made of HPFRCC, design and analysis of an alternative section of cylindrical module. To study the response and use the obtained response in designing the structural system resistant to the blast waves.

\section{Methodology}

The methodology of the work consists of:

1) Design of cylindrical module using limit state method.

2) Preliminary study of Abaqus software.

3) Material modelling.

4) Validation of numerical modelling.

5) Modelling of the structure.

6) Conduct model analysis to obtain natural frequencies and mode shapes.

7) Conduct dynamic explicit analysis.

8) Study the responses.

\section{Design of Cylindrical Module}

The design is made according to the codes IS4991 (1968), IS458 (2003) and IS783 (1985).

\subsection{Dimensions and load parameters}

A cylindrical module of $2.4 \mathrm{~m}$ internal diameter and length $3.9 \mathrm{~m}$ made of SFRCC is designed using limit state method. The module is buried under an earth cover of $1.5 \mathrm{~m}(\mathrm{H})$. It is designed to withstand an overpressure due to blast load of $159 \mathrm{KN} / \mathrm{m}^{2}$ (23psi) plus the overburden pressure due to $1.5 \mathrm{~m}$ of compacted soil having density of $16 \mathrm{KN} / \mathrm{m}^{3}$ on the circumference. Other details include:

- Type B bedding, with a width of trench $(B)=4000 \mathrm{~mm}$.

- $\mathrm{H} / \mathrm{B}$ ratio=0.375

- Settlement ratio, $\left(\mathrm{r}_{\mathrm{s}}\right)=0.5$

- A heavy duty type $\left(\mathrm{NP}_{4} \mathrm{Class}\right)$ of reinforced concrete pipe is considered.

- Angle of internal friction(fully submerged soil $)=45^{0}$

The detailed dimensions of the module are shown in Figure2.

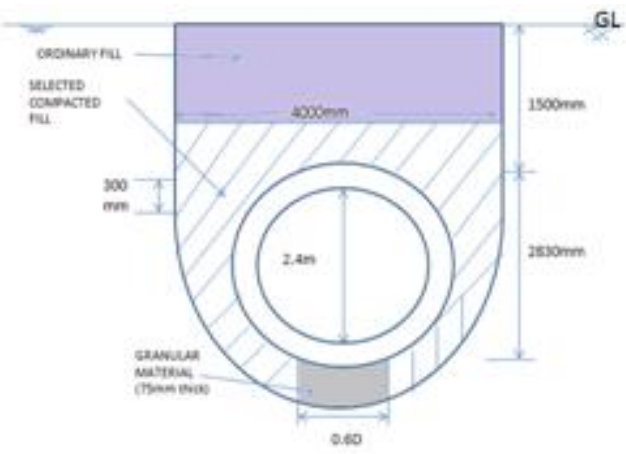

Figure2: Shelter under trench condition

\subsection{Load calculations}

Module is subjected to the following loads:

- Self weight.

- UDL load due to weight of earth fill.

- Earth fill over haunches.

- Uniform and varying earth pressures from sides.

- Superimposed blast load.

The vertical load $\left(\mathrm{W}_{\mathrm{e}}\right)$ on the cylindrical shell due to earth fill material is calculated from the formula: $W_{e}=C_{t} \gamma B^{2}$

Where $C_{t}=0.375$ (obtained from curve $B$ normal wet soil; IS783. A.1)

$\mathrm{W}_{\mathrm{e}}=0.375^{*} 16^{*} 4^{2}=96 \mathrm{KN} / \mathrm{m}$

The vertical load $\left(\mathrm{W}_{\mathrm{u}}\right)$ due to superimposed blast load is calculated from the following formula: $\mathrm{W}_{\mathrm{u}}=\mathrm{C}_{\mathrm{u}} \mathrm{BU}$

Where $C_{u}=0.95$ (obtained from curve $B$ fig5, normal wet soil;IS783)

$\mathrm{W}_{\mathrm{u}}=0.95 * 4 * 159=604.2 \mathrm{KN} / \mathrm{m}$

Required load carrying capacity should be at least: $\left(\mathrm{W}_{\mathrm{e}}+\mathrm{W}_{\mathrm{u}}\right) / \mathrm{F}_{\mathrm{t}}$, where $\mathrm{F}_{\mathrm{t}}=2.2$ ( load factor)

$(96+604.2) / 2.2=318.27 \mathrm{KN} / \mathrm{m}$

The concrete has a minimum compressive strength of $35 \mathrm{~N} / \mathrm{mm}^{2}$ at 28 days. 


\section{International Journal of Science and Research (IJSR) \\ ISSN (Online): 2319-7064}

Index Copernicus Value (2013): 6.14 | Impact Factor (2015): 6.391

According to IS458 (2003) this module should bear the following loads:

(a) load to produce $0.25 \mathrm{~mm}$ crack $=155 \mathrm{KN} / \mathrm{m}$

(b) ultimate load $=232.50 \mathrm{KN} / \mathrm{m}$

Since, the modular design load carrying capacity requirement of $318.27 \mathrm{KN} / \mathrm{m}$ is greater than the maximum or ultimate strength of the cylinder, further strengthening of the module is needed. Figure 3 shows the obtained pressure diagram.

\subsection{Design}

M50 grade SFCC and $\mathrm{F}_{\mathrm{e}} 500$ steel is taken for design, with an effective cover of $50 \mathrm{~mm}$. The thickness of the module obtained is $215 \mathrm{~mm} .16 \mathrm{~mm} \emptyset$ bars@12mm c/c spacing for main hoops and $6 \mathrm{~mm} \emptyset$ bars@85mm c/c spacing for longitudinal (distribution) reinforcement is obtained. The design is made safe against tensile stresses. The reinforcement detailing is as shown in Figure 4.

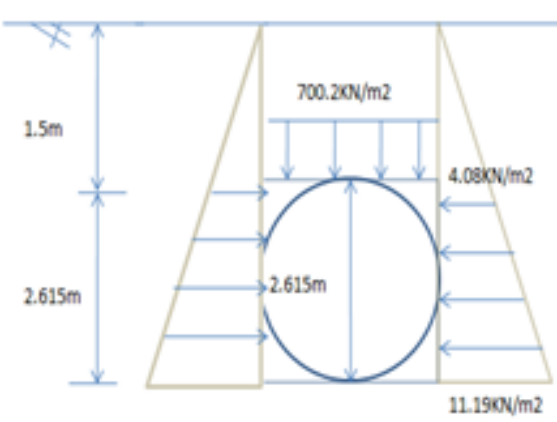

GL

Figure 3: Pressure diagram

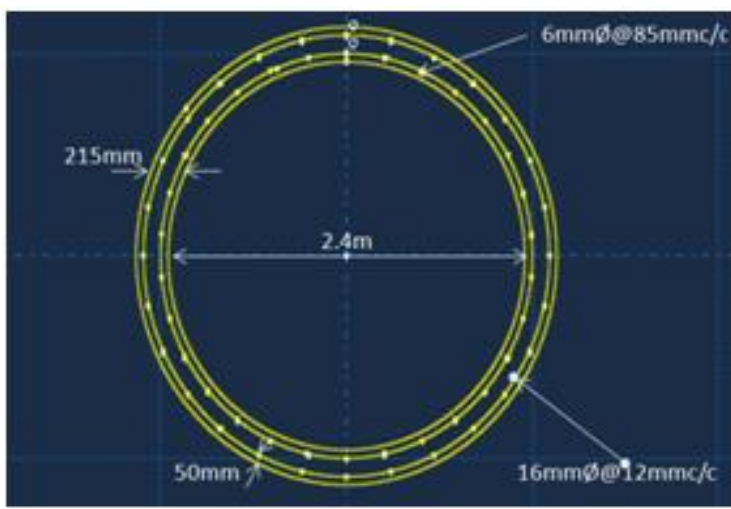

Figure 4: Reinforcement details

\section{Material Model}

\subsection{Concrete Material Model}

To describe the nonlinear dynamic behavior of RC structure subjected to blast loading, many factors like concrete compression hardening, concrete tension stiffening, concrete elasticity, etc are required. Concrete damage plasticity (CDP) model in Abaqus is used to model M50 grade (ultimate compressive strength of $50 \mathrm{MPa}$ ) SFCC. The properties are tabulated in Table 1 .

Table 1: Concrete material property

\begin{tabular}{|c|c|}
\hline Yield strength $\left(\mathrm{f}_{\mathrm{v}}\right)(\mathrm{MPa})$ & 50 \\
\hline Elastic modulus $\left(\mathrm{E}_{\mathrm{C}}\right)(\mathrm{GPa})$ & 35 \\
\hline Poisson's ratio $(v)$ & 0.35 \\
\hline
\end{tabular}

Density $\left(\mathrm{Kg} / \mathrm{m}^{3}\right)$

2550

Figures 5(a) and 5(b) show the stress strain curves for M50 SFCC in compression and tension, respectively(Tomasz Jankowiak, Lodygowski,2005).

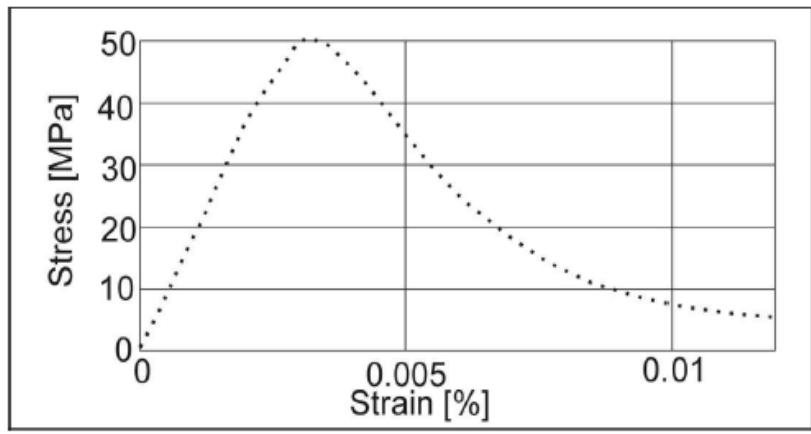

Figure 5 (a) Stress strain curve for M50 SFCC in compression

\section{Numerical Model}

\subsection{Model Description}

The three dimensional finite element model of the cylindrical module has been developed using Abaqus/ CAE6.12. A 3.9m long concrete shell of $215 \mathrm{~mm}$ thick with reinforcement bars of $6 \mathrm{~mm} \varnothing$ in the longitudinal direction and $16 \mathrm{~mm} \varnothing$ hoops about the circumference of the module as per the detailing is modeled. The distance between the inner and outer hoop reinforcement is $115 \mathrm{~mm}$. The steel reinforcement has been embedded in concrete module and modeled using 3D solid revolution in the part option in Abaqus/CAE. Proper bonding between concrete and reinforcement bars has been assured by applying embedded region constrain option available in Abaqus. The bottom plane of the shell in provided with springs with a stiffness of $0.714 \mathrm{~N} / \mathrm{mm}^{2}$. This is done to show the effect of soil in the structure. These springs are provided with fixed boundary condition at the bottom. Element type of eight node reduced integration brick element with hourglass control and finite membrane strains (C3D8R) is adopted in mesh.

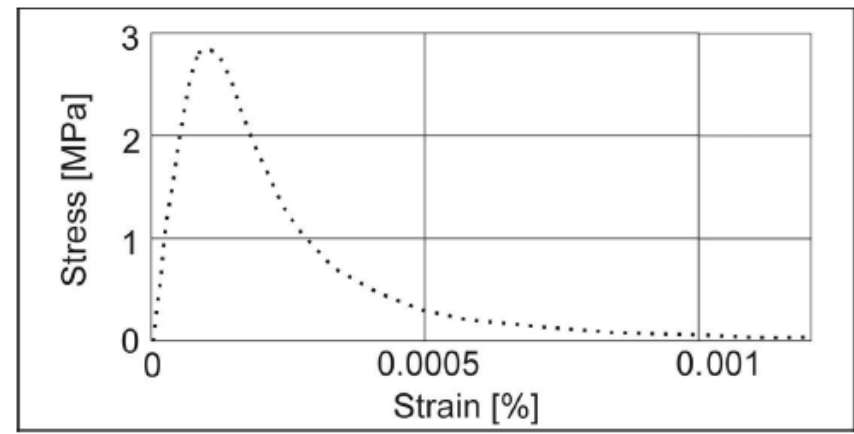

Figure 5(b) Stress strain curve for M50 SFCC in tension

\subsection{Steel and soil material model}

The material properties have been tabulated in Table 2(a) and 2(b).

Table 2(a): Material property for steel

\begin{tabular}{|c|c|}
\hline Yield strength $\left(\mathrm{f}_{\mathrm{y}}\right)(\mathrm{MPa})$ & 500 \\
\hline
\end{tabular}


International Journal of Science and Research (IJSR)

ISSN (Online): 2319-7064

Index Copernicus Value (2013): 6.14 | Impact Factor (2015): 6.391

\begin{tabular}{|c|c|}
\hline Elastic modulus $\left(\mathrm{E}_{\mathrm{C}}\right)(\mathrm{GPa})$ & 200 \\
\hline Poisson's ratio(v) & 0.3 \\
\hline Density $\left(\mathrm{Kg} / \mathrm{m}^{3}\right)$ & 7850 \\
\hline \multicolumn{2}{|c|}{ Table 2(b): Material property for soil } \\
\hline Density $\left(\mathrm{Kg} / \mathrm{m}^{3}\right)$ & 16000 \\
\hline Elastic modulus(MPa) & 5 \\
\hline Poisson's ratio( $(v)$ & 0.45 \\
\hline Friction angle $(\Phi)$ & $45^{0}$ \\
\hline
\end{tabular}

\section{Numerical Analysis}

Model analysis of the module is done to obtain the natural frequency and mode shapes. Dynamic explicit analysis was used to capture the transient and nonlinear behavior of the cylindrical module. The acceleration vs. time graph obtained in dynamic explicit analysis is plotted in Matlab software to obtain the fast fourier transform (FFT) .The results is compared with the natural frequency obtained in model analysis. In dynamic explicit analysis the blast load is given as per the pressure time history as shown in Figure 6 . The analysis was conducted for 0.78 seconds with very small time-step of $0.0001 \mathrm{~s}$. Test runs were carried out to determine the length of analysis and time step and it was found that the above two parameters were adequate in capturing the major response.

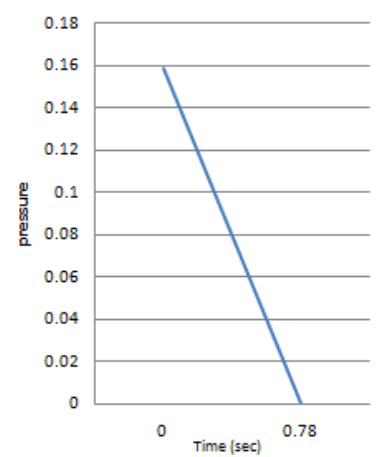

Figure 6: Pressure vs. time graph

\section{Results and Discussions}

\subsection{Model analysis}

Model analysis is done by creating step with linear perturbation frequency option in Abaqus. Ten eigen values are taken to obtain the natural frequency and mode shapes. A low natural frequency is obtained, which is almost to zero value $\left(4.12 * 10^{-6}\right.$ cycles/time). Figure 7 (a) shows the first and second mode shapes and figure 7(b) shows the displacement vs. mode no. plot.

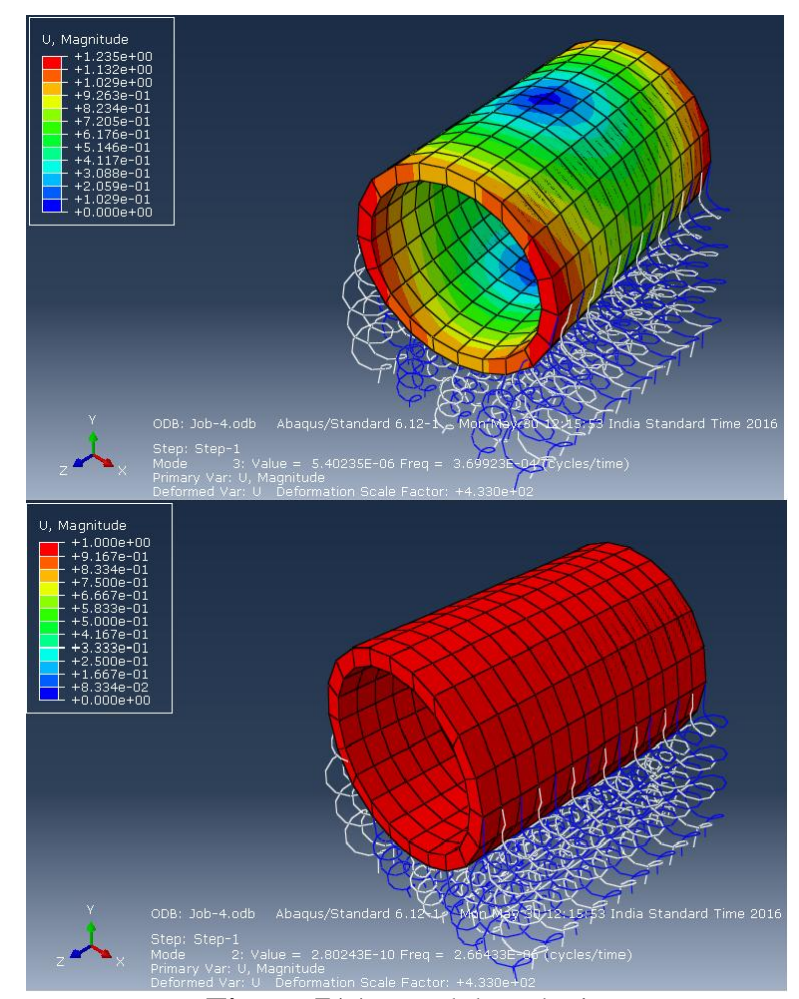

Figure 7(a): Model analysis

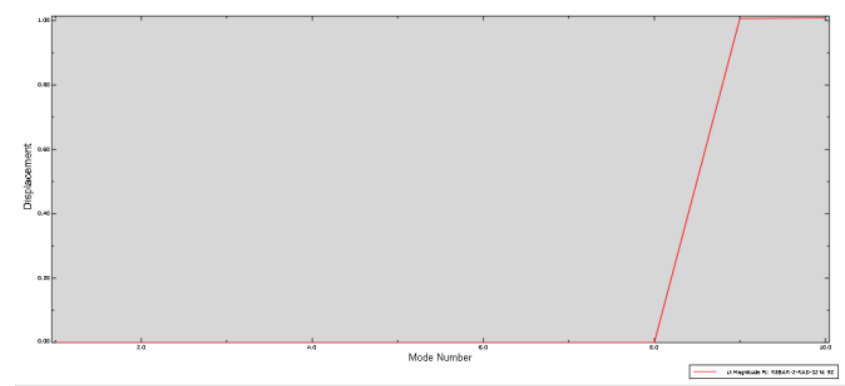

Figure 7(b): Displacement vs. mode number plot

\subsection{Dynamic explicit analysis}

The top surface of the cylindrical module is subjected to blast load. The analysis was conducted for 0.78 seconds with very small time-step of $0.0001 \mathrm{~s}$. The time history displacement at the center point on the top surface of the module is taken (Figure 8). The displacement reaches the maximum value in very short time. The acceleration vs. time plot is also obtained (Figure9), showing a lower value of acceleration. This graph is ploted in Matlab software to obtain the FFT (Figure10). The peak value of frequency display good agreement with the natural frequency obtained in the model analysis. The cylindrical module is displaced to a minimum value about $8 \mathrm{~mm}$, figure 11(a) and 11(b) shows the deformed shape and stress vs. time plot respectively in Abaqus. 


\section{International Journal of Science and Research (IJSR) \\ ISSN (Online): 2319-7064}

Index Copernicus Value (2013): 6.14 | Impact Factor (2015): 6.391

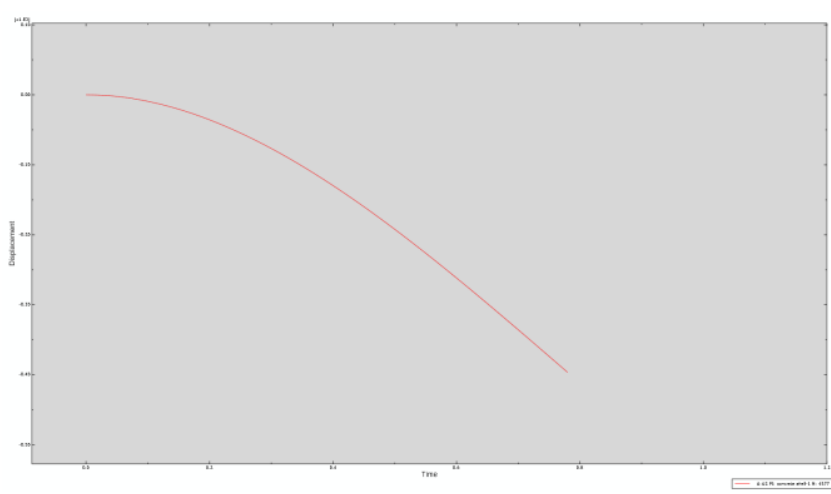

Figure 8: Displacement vs. time plot

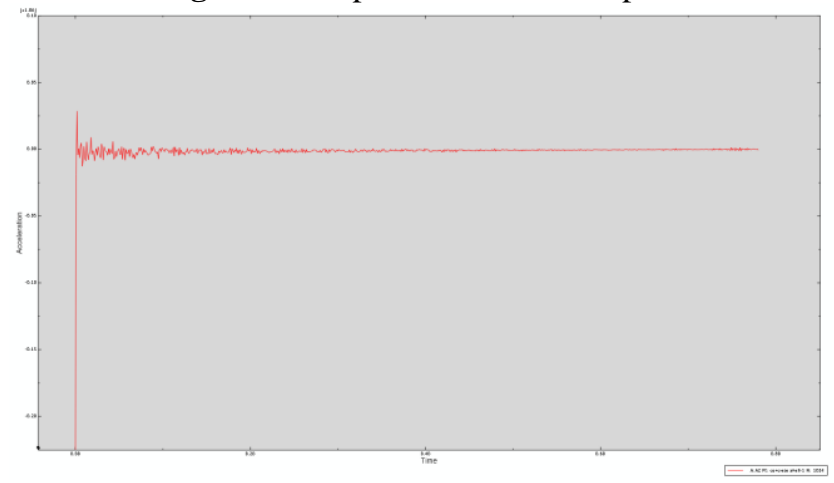

Figure 9: Acceleration vs. time plot

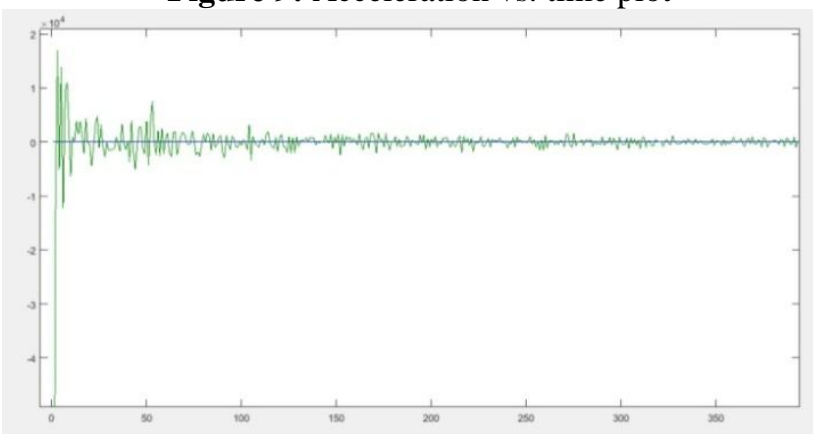

Figure 10: FFT plot (frequency vs. amplitude plot)
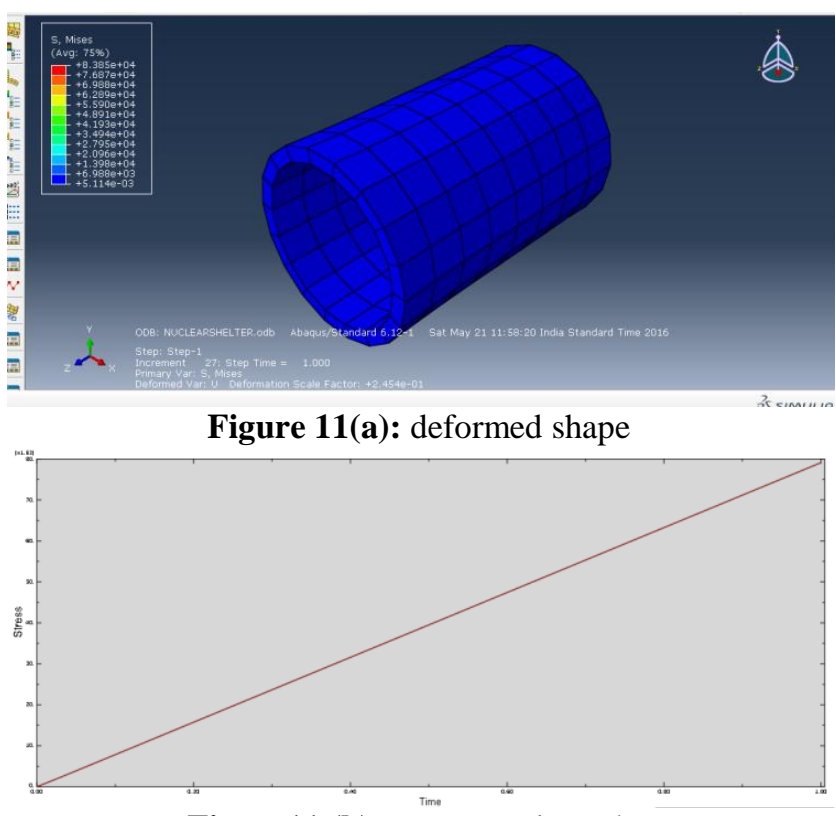

Figure11 (b): stress vs. time plot

\subsection{Applications}

From the evaluation of the analytical results, it was observed that the shelter designed manually by limit state method is safe against the blast load, since a minimum deformation was observed. These shelters as the following applications:

- The shelter can be made for personal protection from blast, thermal and radiation effects in case of accidental explosion or war scenario.

- It can also be used for communication, first aid, and command or control centers.

- The shelter can be further utilized for the storage of materials, such as food, fuel, medical supplies, etc.

\section{Conclusions}

In the present study, three dimensional nonlinear finite element analysis of underground blast resistant cylindrical shelter have been carried out. Abaqus explicit analysis is used to study the nonlinear behavior towards blast loads. The following conclusions are obtained:

- The analytical results shows that a minimum deformation of about $8 \mathrm{~mm}$ is occurring in the dynamic explicit analysis, hence the shelter is safe against the blast load.

- Shelter has a low value of natural frequency, the peak value of frequency of structure when subjected to blast load display good agreement with the natural frequency.

- Study on the concrete damage plasticity model of concrete helped to create a link between the real behavior of concrete and its numerical modeling.

- Shelter manually designed using codes in limit state method is verified with the analytical analysis and concluded that the shelter is safe against blast load (designed pressure of 23psi).

\section{Scope of Future Study}

Further study can be done varying the parameters like input energy, stand-off distance and shelter properties, etc. on the stresses at critical points on the structure.

\section{References}

[1] Indian standard code for practice, criteria for blast resistant design of structures for explosions above ground IS: 4991-1968, Bureau of Indian Standards, August 1993,New Delhi.

[2] Design Aid For Reinforced Concrete IS :456-2000

[3] Indian Standard Code Of Practice For Laying Of Concrete Pipes (First Revision), December 2000.

[4] Indian Standard Code Of Precast Concrete Pipes (With And Without) Reinforcement, Specification (Fourth Revision), November 2007.

[5] ABAQUS Theory Manual, version 6.3, Hibbitt KarlsonB \& Sorensen, Inc 2002.

[6] Slawson, T. R. \& Davis, J.L. "Behaviour Of A Reinforced Concrete B1ast Shelter In An Overload Environment",59th Shock and Vibration Symposium, Vol. 3, USA, 1988. pp. 231-42.

[7] Homes, R. Loodson, S.C. \& Slawson, T. R. Shelter, "Response In A Simulated Eight. Kt Nuclear Blast 


\section{International Journal of Science and Research (IJSR) \\ ISSN (Online): 2319-7064}

Index Copernicus Value (2013): 6.14 | Impact Factor (2015): 6.391

Environment". 59th Shock and Vibration Symposium, Vol.13, USA, 1988. pp. 243-57.

[8] Manmohan Dass Goe and Vasant A. Matsagar, "BlastResistant Design Of Structures", American Society of Civil

Engineers,DOI:10.1061/(ASCE)SC.19435576000188,20 14.

[9] Tiwari, T. Chakraborty and V. Matsagar,Dynamic "Analysis Of Underground Tunnel Subjected To Internal Blast Loading” ,6th European Conference on Computational Fluid Dynamics (ECFD VI) R.

[10] Huabei Liu ," Dynamic Analysis of Subway Structures Under Blast Loading “ , 22 August 2009 / Published online: 17 September 2009 ,Springer Science+Business Media B.V. 2009.

[11] Tomasz Jankowiak, "Identification Of Parameters Of Concrete Damage Plasticity Constitutive Model", foundation of civil environmental engineering vol.no.6, 2005.

\section{Author Profile}

Geethu Elsa Thomas is M.Tech. Student, Structural Engineering, Sree Buddha College of Engineering. She did Bachelor of Engineering in civil Engineering from Anna University, Chennai. Residence: Perayil Roji Bhavan ,Adoor p o, Pathanamthitta , pin:691523

Sithara .S is Assistant Professor, Department of Civil Engineering, Sree Buddha College of Engineering. Did Master of Technology in Hydraulics Engineering from University of Kerala and Bachelor of Technology in civil Engineering from University of Kerala. Residence : Ajay Bhavanam, Muthukattukara, Noornadu p o, Alappuzha pin: 690504 